Meta

Journal des traducteurs

Translators' Journal

\title{
Deficiencias del texto de partida en la traducción de textos destinados a la enseñanza y divulgación de la ciencia
}

\section{Carlos Garrido}

Volume 60, numéro 3, décembre 2015

URI : https://id.erudit.org/iderudit/1036138ar

DOI : https://doi.org/10.7202/1036138ar

Aller au sommaire du numéro

\section{Éditeur(s)}

Les Presses de l’Université de Montréal

ISSN

0026-0452 (imprimé)

1492-1421 (numérique)

Découvrir la revue

Citer cet article

Garrido, C. (2015). Deficiencias del texto de partida en la traducción de textos destinados a la enseñanza y divulgación de la ciencia. Meta, 60(3), 454-475. https://doi.org/10.7202/1036138ar

\section{Résumé de l'article}

Le présent article définit et délimite de façon précise le concept de déficience ou défaut dans le texte de départ lors de la traduction communicative de textes scientifiques didactiques et de vulgarisation, tout en le différenciant d'autres concepts voisins (comme les passages qui suscitent chez le traducteur l'introduction d'améliorations, des passages inexacts dus à une légitime simplification pédagogique, etc.). Par la suite, l'article propose une classification spécifique de ces déficiences, à partir d'un vaste échantillon de traductions vers l'espagnol et le portugais, publiées et inédites (réalisées par l'auteur), de fragments d'articles d'encyclopédie, de manuels et de livres et articles de vulgarisation rédigés en anglais et en allemand. La classification proposée des déficiences qui apparaissent fréquemment dans les textes d'origine destinés à l'enseignement et la vulgarisation de la science et qui doivent être corrigées dans le corps du texte cible de la traduction, établit une distinction, au niveau hiérarchique supérieur, entre déficiences factuelles d'une part, en contradiction avec la désignation de la vérité connue ou avec une correspondance adéquate entre les composants verbal et iconique du texte (six sous-catégories) et déficiences formelles d'autre part, qui lèsent la rigueur expressive ou l'efficacité communicative (huit sous-catégories). Finalement, l'article analyse les diverses exigences cognitives liées à la détection et la correction de telles déficiences dans le cadre de la traduction communicative. 


\title{
Deficiencias del texto de partida en la traducción de textos destinados a la enseñanza y divulgación de la ciencia
}

\author{
CARLOS GARRIDO \\ Universidade de Vigo. Vigo, España \\ cgarrido@uvigo.es
}

\section{RÉSUMÉ}

Le présent article définit et délimite de façon précise le concept de déficience ou défaut dans le texte de départ lors de la traduction communicative de textes scientifiques didactiques et de vulgarisation, tout en le différenciant d'autres concepts voisins (comme les passages qui suscitent chez le traducteur l'introduction d'améliorations, des passages inexacts dus à une légitime simplification pédagogique, etc.). Par la suite, l'article propose une classification spécifique de ces déficiences, à partir d'un vaste échantillon de traductions vers l'espagnol et le portugais, publiées et inédites (réalisées par l'auteur), de fragments d'articles d'encyclopédie, de manuels et de livres et articles de vulgarisation rédigés en anglais et en allemand. La classification proposée des déficiences qui apparaissent fréquemment dans les textes d'origine destinés à l'enseignement et la vulgarisation de la science et qui doivent être corrigées dans le corps du texte cible de la traduction, établit une distinction, au niveau hiérarchique supérieur, entre déficiences factuelles d'une part, en contradiction avec la désignation de la vérité connue ou avec une correspondance adéquate entre les composants verbal et iconique du texte (six souscatégories) et déficiences formelles d'autre part, qui lèsent la rigueur expressive ou l'efficacité communicative (huit sous-catégories). Finalement, l'article analyse les diverses exigences cognitives liées à la détection et la correction de telles déficiences dans le cadre de la traduction communicative.

\section{ABSTRACT}

The following article accurately defines and demarcates the concept of source text error within the framework of the communicative translation of scientific texts with a didactic or popularizing character, as distinguished from various other closely related concepts (such as text passages inducing the introduction of improvements, or inaccurate passages originating in a legitimate pedagogical simplification, etc.). It also advances a specific classification of those textual errors resorting to the analysis of a rich collection of published and unpublished (author-made) translations into Spanish and Portuguese of excerpts of English and German encyclopedia articles, textbooks, popularizing articles and popularizing books with scientific content. Errors that occur in source texts aimed at science education and popularization, which come up rather frequently and must be corrected in the body of the target text in a communicative translation, are here classified, in the highest hierarchical level, into factual errors, when opposed to the designation of known truth or to the proper conformity between verbal and iconic components of text (six subcategories), and formal errors, when harming expository correctness or communicative efficiency (eight subcategories). In addition, the article assesses the varying cognitive requirements imposed on the translator by the necessity of spotting and rectifying those errors in a communicative translation. 


\section{MOTS-CLÉS/KEYWORDS}

communication scientifique extradisciplinaire, déficience du texte de départ, enseignement et vulgarisation de la science, traduction scientifique et technique extradisciplinary science communication, errors in the source text, science education and popularization, scientific-technical translation

\section{Introducción}

La corrección en la traducción de deficiencias o defectos presentes en el texto de partida constituye exigencia de una traducción de carácter prospectivo, orientada al texto de llegada, como son, por lo general, las traducciones de textos científico-técnicos actuales (Schmitt 1999a: 59-61; Schmitt 1999b: 148; Horn-Helf 1999: 163), las cuales se pautan por el modelo de la denominada traducción comunicativa, o traducción-instrumento (Reiß y Vermeer 1991; Nord 1989, 1997, 2012). De hecho, en la traducción de textos especializados, la corrección de las deficiencias del texto de partida corresponde a un concepto profesional de calidad, como explican en el siguiente fragmento Fleischmann y Schmitt:

Diese Sichtweise [die der kommunikativen Übersetzung] ist zwar nicht unwidersprochen, sie deckt sich jedoch mit den Kriterien des Qualitätsmanagement (z. B. nach Iso 9000 ff. [...]), bei dem Qualität ebenfalls ergebnisorientiert definiert ist: Ein Qualitätsmangel liegt vor, wenn ein Produkt seinen Zweck (bzw. die Kundenerwartungen) nicht erfüllt. Nachrangig (für den Produktkunden) ist die Frage nach den Ursachen der Mängel. Gehen Produktmängel (also auch Übersetzungsmängel) auf Mängel im Ausgangsmaterial (hier: im Ausgangstext) zurück, so ist das zwar eine Erklärung, jedoch keine Rechtfertigung. (Fleischmann y Schmitt 2004: 536)

Aunque esta perspectiva [la de la traducción comunicativa] no esté libre de objeciones, sin embargo se corresponde con los criterios de gestión de la calidad (por ejemplo, según Iso 9000 y ss. [...]), que también definen la calidad en función del resultado: se registra, así, un déficit de calidad cuando un producto no alcanza su finalidad (o no satisface las expectativas de los clientes), revelándose aquí secundaria (para los clientes del producto) la cuestión relativa a las causas de la deficiencia. En el caso de que las deficiencias del producto (por tanto, también las deficiencias de la traducción) se originen en deficiencias del material de partida (aquí: del texto de partida), ello constituirá, sin duda, una explicación, pero no una justificación. (traducción del autor)

Por otro lado, dadas las notables exigencias cognitivas que plantea al traductor, y dada la magnitud de las correspondientes alteraciones textuales, la corrección en la traducción de deficiencias presentes en el texto de partida representa una de las principales categorías de modificación substancial de la traducción comunicativa de textos especializados (Garrido 2010), y, junto con la adaptación naturalizadora de discordancias interculturales, constituye un factor determinante del carácter creativo que reviste la traducción de textos científicos y técnicos (Schmitt 2005: 104). Además, aspecto adicional que subraya la importancia de analizar el problema traductivo que para la traducción especializada representan las deficiencias del texto de partida, es el hecho de que tales defectos afligen a una elevada proporción de los textos (científico-)técnicos, como indica Schmitt: 
Rückblickend auf über zwei Jahrzehnte Berufstätigkeit im Bereich technischer Übersetzungen im ganzen Spektrum einschlägiger Textsorten ist festzustellen, daß mit Defekten prinzipiell in allen technischen Texten zu rechnen ist: „lebende Texte sind defekte Texte" (HöNIg 1998: 162), wenngleich mit unterschiedlicher Wahrscheinlichkeit. (Schmitt 1999a: 61)

Tomando en consideración mi actividad profesional de más de dos decenios en el campo de la traducción técnica, durante los cuales trabajé con toda la gama de géneros textuales de ese ámbito, puedo decir que, en principio, se debe contar con la presencia de deficiencias en todos los textos técnicos, ya que "los textos vivos son textos defectuosos" (Hönig 1998: 162), si bien lo son con diferentes probabilidades. (traducción del autor)

Dos autores han estudiado en profundidad el fenómeno de la presencia de deficiencias en el texto de partida técnico y su tratamiento en la traducción comunicativa: Schmitt (1999a: 59-106) y Horn-Helf (1999: 162-210). Schmitt clasifica las deficiencias de los textos de partida del ámbito de la técnica en ocho categorías: a) falta o duplicación indebida de fragmentos textuales (1999a: 62-63); b) cifras y unidades de medida erradas (1999a: 63-65); c) errores tipográficos que alteran el sentido 1999a: 65-67); d) discrepancia entre el componente verbal del texto y la imagen (pág. 68-82); e) discrepancia entre el texto y la realidad del producto técnico (1999a: 83-85); f) deficiencias que dificultan la comprensión del texto de partida (1999a: 86-94), en la macroestructura textual, en la microestructura textual, en el nivel oracional y en el nivel de los sintagmas y palabras; g) deficiencias de expresión (1999a: 94-98), y h), deficiencias de contenido (1999a: 98-103). A su vez, Horn-Helf propone una clasificación muy circunstanciada de las deficiencias de los textos técnicos, en cuyo nivel jerárquico superior figuran seis categorías, cada una de las cuales aparece subdividida en numerosas subcategorías: a) deficiencias en los niveles del lexema o del término (1999: 166-175); b) deficiencias en el nivel sintagmático (1999: 175-199); c) deficiencias en el nivel de la oración (1999: 178-199); d) deficiencias en el nivel de los bloques textuales (1999: 199-204); e) deficiencias en el nivel textual (1999: 204-206), y f), deficiencias en el nivel del mundo textual (1999: 206-207).

En un momento como el presente, en que la comunicación científica extradisciplinaria goza de gran relevancia social, y no sólo en su cariz instructivo y profesionalizante, sino también como configuradora de la cultura general de amplias capas de la población y como elemento de unión entre el mundo de la investigación y la opinión pública (Niederhauser 1999: 229), es objetivo del presente trabajo concebir una categorización específica, convenientemente ejemplificada, de las deficiencias presentes en los textos destinados a la enseñanza y divulgación de la ciencia y ofrecer orientación sobre su correspondiente tratamiento traductivo. En este sentido, se revelará necesario reflexionar sobre la delimitación precisa en este ámbito del concepto de 'deficiencia textual' y prestar atención a los dos valores primordiales de la comunicación especializada (denominados invariantes absolutas de la traducción comunicativa de textos científico-técnicos en Garrido [2010]): designación de la verdad (conocida en cada época), por una parte, y eficacia comunicativa y rigor expresivo, por otra. Para la realización del inventario de tipos de deficiencias textuales, y para la inclusión de los respectivos ejemplos de traducción, se ha recurrido aquí a la experiencia del autor (que tiene formación universitaria en biología) como traductor (al castellano [es en los ejemplos que siguen] y al gallego-portugués [ $p t]$ ) de tres libros didácticos de biología sistemática y evolutiva (ver en Anexo estas y otras 
fuentes de los ejemplos aquí aducidos), como lector habitual durante años de revistas de divulgación científica compuestas en cuatro lenguas y como profesor de traducción científico-técnica del inglés (en) y del alemán (de), actividad docente, ésta, que ha llevado al redactor de estas líneas a estudiar desde un punto de vista traductivo una gran cantidad de artículos de enciclopedia, de obras didácticas y de libros y artículos divulgativos de los más diversos asuntos científicos.

\section{Definición y delimitación de las deficiencias del texto de partida en la traducción comunicativa de textos científicos didácticos y divulgativos}

En el marco de la traducción comunicativa de textos destinados a la enseñanza y divulgación de la ciencia, entendemos por deficiencias del texto de partida aquellas circunstancias plasmadas en el documento que sirve al traductor de oferta informativa inicial que en este contrarían o perjudican ora la designación de la verdad conocida (en la respectiva época) o la adecuada correspondencia entre los componentes verbal e icónico del texto, ora la eficacia comunicativa o rigor expresivo, cuando tales circunstancias no surgen de modo intencionado persiguiendo un designio (legítimo) diferente del informativo, no se deben a un mero desfase temporal significativo entre la producción y la recepción textuales (información anticuada) y no se subordinan a una estrategia comunicativa encaminada a tornar accesible información especializada a unos destinatarios que no son especialistas (simplificación didáctica o pedagógica).

Así, en este contexto, cabe excluir de la categoría de deficiencias textuales los contenidos falsos que, de modo intencionado y con finalidad humorística, los redactores ocasionalmente vehiculan en ciertos artículos lexicográficos de especialidad o en ciertos artículos de divulgación científica. Un ejemplo célebre de esta infiltración del humor en la comunicación científica es el artículo consagrado al inverosímil «piojo de las piedras» (al. Steinlaus) que se incluye en el prestigioso diccionario alemán de medicina clínica Pschyrembel (Ziegler 2010), cuyo inicio, en la 261 a edición de la obra (año 2007), es el siguiente:

(1) de: Steinlaus: (engl.) stone louse; syn. Petrophaga lorioti [sic]; kleinstes einheim. Nagetier (Größe 0,3-3 mm; s. Abb.) aus der Fam. der Lapivora [sic]; Erstbeschreibung 1983, tatsächl. eines der ältesten erdgeschichtl. Organismen (fossile Funde); vermutl. urgeschichtl. Einschleppung auf die Erde durch Meteoriteneinschläge; [...]. (Pschyrembel: s.v. 'Steinlaus')

es: piojo de las piedras s.m. (ingl. stone louse; n. cient. Petrophaga lorioti). El más pequeño de los animales de hábitos roedores de Europa (0,3-3 mm de longitud; v. ilustr.), insecto de la fam. Lapivoridae; descrito por primera vez en 1983, se trata de uno de los organismos filogenéticamente más antiguos (hallazgos fósiles); probable introducción en el planeta Tierra a través del impacto de meteoritos. (traducción del autor $)^{1}$

También con finalidad humorística, lúdica, es costumbre en algunos países incluir alguna noticia falsa en los periódicos un día determinado del año, señalado en el calendario como jornada dedicada a las bromas o «inocentadas». Tal día es en España, como se sabe, el 28 de diciembre, día de los Santos Inocentes, y en Alemania (y en otras partes de Europa), el 1 de abril, jornada de las Aprilscherze o «bromas de abril». En Alemania, la tradición de las Aprilscherze rige, incluso, en algunas revistas de divulgación científica, cuyo número de abril puede acoger informaciones falsas 
más o menos estrambóticas, como muestra el siguiente ejemplo, correspondiente a un artículo aparecido en la, por lo demás, seria y rigurosa Naturwissenschaftliche Rundschau, que anuncia la construcción de un embalse gigantesco en el Rhin que anegará por completo las ciudades de Mannheim, Ludwigshafen, Heidelberg, Karlsruhe y Estrasburgo (a seguir transcribimos el título, el resumen y el primer párrafo de este artículo firmado por «Prof. Dr. Ottokar H. Fürchterlich»):

(2) de: EU plant Großstaudamm am Oberrhein // Fachleute rechnen in diesem Jahrhundert wegen des bevorstehenden Klimawechsels mit einem erhöhten Hochwasserrisiko am Rhein. Dagegen soll nach Willen der Anrainerstaaten rechtzeitig Vorsorge getroffen werden. Ein internationales Gremium aus Politik und Wissenschaft hat nun einen Vorschlag vorgelegt. // Bei einer Klausurtagung beschlossen die Umwelt- und Wirtschaftsministerien der EU-Länder Frankreich, Deutschland und Niederlande in München den Bau eines Großstaudamms am Oberrhein, um vor allem die Gefahren durch das Rheinhochwasser zu minimieren. Der geplante Stausee wird eine Länge von $200 \mathrm{~km}$ und eine Breite von knapp 40 km haben. Die Städte Mannheim, Ludwigshafen, Heidelberg, Karlsruhe, Straßburg u. a. werden komplett überschwemmt. (Fürchterlich, 2007: 207)

es: La UE planea la construcción de una enorme presa en el Alto Rhin // Por culpa del inminente cambio climático, los expertos preven un riesgo elevado de inundación a orillas del Rhin a lo largo del presente siglo, de modo que los países ribereños deberán adoptar las oportunas medidas preventivas. En ese sentido, un grupo internacional integrado por políticos y científicos acaba de presentar ahora una propuesta. // En una sesión celebrada a puerta cerrada en Múnich, los ministerios de economía y de medio ambiente de Francia, Alemania y Países Bajos han resuelto construir en el Alto Rhin una gran presa con el objetivo de minimizar, sobre todo, el riesgo de inundaciones causadas por ese río. El embalse previsto tendrá una longitud de $200 \mathrm{~km}$ y una anchura de casi $40 \mathrm{~km}$ y anegará por completo, entre otras, las ciudades de Mannheim, Ludwigshafen, Heidelberg, Karlsruhe y Estrasburgo. (traducción del autor)

Tampoco, por supuesto, deben conceptuarse como deficiencias factuales los casos en que alguna información proporcionada en el texto de partida, y que estaba vigente en el momento de la composición original, se revele anticuada, posteriormente, en el momento de la traducción; aunque en tal circunstancia, por consiguiente, el traductor no está llamado a realizar una corrección en la traducción, sí tendrá que introducir una modificación substancial (con alteración de la designación original) bajo la forma de actualización informativa (Garrido 2010). Por el contrario, sí cabe hablar de deficiencia factual cuando la falta de actualidad de la información ya se registre en el momento en que el texto (de partida) es producido o publicado, y en tales casos la intervención del traductor adopta propiamente la forma de corrección. A seguir, ilustramos con un ejemplo las actualizaciones informativas que el traductor eventualmente debe introducir en una traducción comunicativa (ejemplo 3, con inserción de la información actualizada en el cuerpo del texto: "comentario interno», en la terminología de Nord [1989]):

(3) en: Organic compounds containing chlorine, bromine, or iodine are fluorinated to produce compounds such as dichlorodifluoromethane $\left(\mathrm{Cl}_{2} \mathrm{CF}_{2}\right)$, the coolant used in most household refrigerators and air conditioners and the propellant widely used to disperse aerosols such as insecticide and paint sprays. (Enc. Brit.: s.v. 'fluorine') es: Los compuestos orgánicos de cloro, bromo o yodo pueden fluorarse para producir sustancias como el diclorodifluorometano $\left(\mathrm{Cl}_{2} \mathrm{CF}_{2}\right)$, uno de los denominados 
clorofluorocarburos o cfc, utilizados como refrigerantes en frigoríficos domésticos y aparatos de aire acondicionado, y como propulsores de aerosoles en pulverizadores de insecticidas y pinturas. No obstante, como se descubrió que los cfc dañan la capa de ozono atmosférica, a partir de 1989 (Protocolo de Montreal) su uso industrial ha sido abandonado progresivamente en todo el mundo. (traducción del autor)

Para redondear esta delimitación del concepto de 'deficiencia del texto de partida' en la traducción comunicativa de textos científicos didácticos y divulgativos, aún debemos tener en cuenta, en primer lugar, que no podrán juzgarse defectuosos aquellos pasajes textuales que vehiculen una información declaradamente imprecisa o incompleta, cuando tal circunstancia se verifique intencionadamente, y en un ámbito conceptual y en un contexto (didáctico, divulgativo) adecuados, con el objetivo de facilitar la inteligibilidad y asimilación del texto por parte de un público lego o no especialista, simplificación pedagógica, ésta, que ilustramos más abajo (ver ejemplo 18); en segundo lugar, tampoco podrán conceptuarse estrictamente como deficiencias del texto de partida aquellos pasajes que susciten en el traductor la introducción de mejoras (factuales o formales), las cuales consisten en la incorporación de informaciones complementarias (casi siempre en nota) o de precisiones designativas concernientes a asuntos tratados en el original y que, respondiendo frecuentemente al prurito didáctico del traductor, son, a diferencia de las correcciones, de carácter meramente facultativo en la traducción comunicativa. Dos ejemplos de introducción de mejoras por parte del traductor son los siguientes:

(4) de: Die großtechn. Darstellung von Aluminium geschieht i. A. in zwei Arbeitsgängen. Zunächst wird Aluminiumoxid aus dem Bauxit nach dem Bayer-Verfahren gewonnen. (Brockhaus-NT: s.v. 'Aluminium')

es: La producción industrial del aluminio tiene lugar por lo general en dos etapas. En primer lugar, se obtiene óxido de aluminio (alúmina) a partir de la bauxita mediante el proceso de Bayer. (traducción del autor)

Comentario: Adición en la traducción del término alúmina (en alemán es más raro el término Tonerde que en español alúmina).

(5) $\boldsymbol{d e}$ : In die Bewertung kann fallweise das zeitliche Auftretren von Merkmalen in der Ontogenese eingehen, ferner auch die stratigraphische Abfolge fossil überlieferter Merkmalsträger in der Zeit. (Systematik in der Biologie: 75)

es: En la evaluación, según las circunstancias, se puede introducir el momento de aparición de los caracteres en la ontogenia, así como la sucesión estratigráfica en el tiempo de los organismos fosilizados que portan los caracteres32. [...] [nota a pie de página:] 32 Merkmalsträger (= "portadores de caracteres") en el original; en la terminología de W. Hennig, "semaforontes". (N. del T.) (La sistemática biológica: 87)

\section{Clasificación y tratamiento de las deficiencias del texto de partida en la traducción comunicativa de textos científicos didácticos y divulgativos}

En contraste con las propuestas de Schmitt (1999a: 59-106) y de Horn-Helf (1999: 162-210), en nuestra clasificación de las deficiencias presentes en los textos (de partida) destinados a la enseñanza y divulgación de la ciencia parece tan natural como práctico establecer una primera dicotomía, basada en la consideración de los dos valores primordiales de la comunicación especializada (v. supra), entre deficiencias factuales 
y deficiencias formales. Así, son factuales aquellas deficiencias del texto de partida que contrarían o perjudican la designación de la verdad conocida (en la respectiva época) o que distorsionan la adecuada correspondencia entre los componentes verbal e icónico del texto; son formales aquellas deficiencias del texto de partida que perjudican la eficacia comunicativa o el rigor expresivo. El ejemplo y el cuadro que siguen servirán para aclarar esta categorización de las deficiencias del texto de partida:

(6) de: Der dänische Chemiker Jöns Jakob Berzelius leitete den Namen [Katalyse] vom

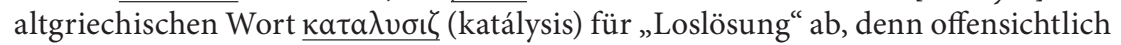
nahmen diese Stoffe an der Reaktion nicht teil. (TechMax, 10: 1)

es: El químico sueco Jöns Jacob Berzelius instauró tal término [catálisis] a partir

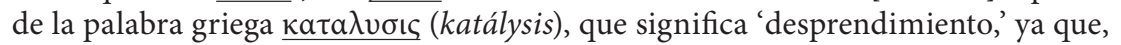
por lo visto, estas sustancias no participaban en la reacción. (traducción del autor) Comentario: En este caso, la versión española corrige una deficiencia factual presente en el original, pues el químico Jöns Jacob Berzelius (1779-1848) no fue danés, como se afirma, sino sueco, y dos deficiencias formales, ya que en el étimo griego transcrito en el original figura indebidamente una $\zeta$ (= zeta) por una $\varsigma$ (= sigma) y dado que en el segundo nombre de bautismo de Berzelius la grafía correcta, la usual en sueco, es Jacob.

Cuadro sinóptico (1) de la clasificación de las deficiencias del texto de partida en la traducción comunicativa de textos destinados a la enseñanza y divulgación de la ciencia.

\begin{tabular}{|c|c|c|}
\hline \multirow[t]{6}{*}{ Deficiencias factuales } & \multicolumn{2}{|c|}{ Lapsos tipográficos que alteran el sentido } \\
\hline & \multicolumn{2}{|c|}{ Lapsos en la consignación de cantidades o unidades de medida } \\
\hline & \multicolumn{2}{|c|}{ Lapsos léxicos } \\
\hline & \multicolumn{2}{|l|}{ Lapsos de redacción } \\
\hline & \multicolumn{2}{|c|}{ Errores conceptuales o de contenido } \\
\hline & \multicolumn{2}{|c|}{ Discrepancia entre los componentes verbal e icónico del texto } \\
\hline \multirow[t]{8}{*}{ Deficiencias formales } & \multirow{4}{*}{$\begin{array}{l}\text { que dificultan la } \\
\text { comprensión }\end{array}$} & Lapsos tipográficos \\
\hline & & Deficiencias léxicas o sintagmáticas \\
\hline & & Deficiencias en el nivel oracional \\
\hline & & Deficiencias en la microestructura textual \\
\hline & \multirow{4}{*}{$\begin{array}{l}\text { que perjudican el rigor } \\
\text { expresivo }\end{array}$} & Ruptura de las convenciones ortotipográficas \\
\hline & & Lapsos tipográficos en la consignación de datos \\
\hline & & Errores léxicos \\
\hline & & Redacción deficiente \\
\hline
\end{tabular}

\subsection{Deficiencias factuales del texto de partida}

Clasificamos las deficiencias factuales del texto de partida en seis categorías: a) lapsos tipográficos que alteran el sentido pertinente; b) lapsos en la consignación de cantidades o unidades de medida; c) lapsos léxicos; d) lapsos de redacción; e) errores conceptuales o de contenido, y f), discrepancia entre los componentes verbal e icónico del texto.

Desde un punto de vista metodológico, cabe señalar, en primer lugar, que, como muestran los ejemplos que siguen, las correcciones de deficiencias factuales son introducidas en la traducción comunicativa, en la mayor parte de los casos, en el cuerpo del texto de llegada («comentario interno»), sin advertir al receptor de la traducción de la existencia de error en el original (en correspondencia con el ideal de 
«traducción encubierta»: House 1981), aunque, en algunos pocos casos (por ejemplo, cuando se juzgue de especial interés promover la rectificación de un error muy difundido en la bibliografía), el traductor podrá dejar constancia de la enmienda efectuada formulando (con la anuencia del autor del texto de partida) tal corrección, de forma documentada, como nota (ver ejemplo 17); en segundo lugar, en caso de que el traductor vierta artículos de revista divulgativa con cierto retraso respecto a la publicación de los originales, podrá revelarse de utilidad consultar la eventual sección de errata de números posteriores de la revista original, por la posibilidad de encontrar en ella, precisamente, la denuncia y corrección de errores (factuales) del correspondiente texto de partida.

\subsubsection{Lapsos tipográficos que alteran el sentido pertinente}

Los textos científicos didácticos y divulgativos, sometidos a procesos de revisión editorial, se encuentran entre los géneros textuales científico-técnicos menos propensos a los lapsos tipográficos, aunque en ellos no se puede excluir por completo tal categoría de deficiencias, las cuales, en algunos casos, distorsionan las palabras hasta el extremo de transmutarlas en otras y alterar de forma sibilina su sentido, con el consiguiente riesgo de engaño para el traductor, como muestra el siguiente ejemplo:

(7) de: Stammzellen, Zellen höherer Organismen, die selbst nicht entdifferenziert sind und die die Fähigkeit zu unbegrenzter Zellteilung besitzen. Bei Teilung können die Tochterzellen identisch mit der Stammzelle sein (Selbsterneuerung) oder einen Entwicklungsweg zu enddifferenzierten Zellen nehmen. Die Differenzierung wird durch das genet. Programm der Zellen oder durch von außen einwirkende Faktoren (Differenzierungsfaktoren) induziert. Alle Gewebe und Organe mit Ausnahme der Nerven- und Muskelzellen[,] die nicht regenerationsfähig sind, werden in wenigen Monaten durch kontinuierl. Abbau und Wiederaufbau erneuert. Da entdifferenzierte Zellen die Fähigkeit zur Zellteilung verloren haben, ist die Differenzierung aus Stammzellen der einzige Weg zur Regeneration. (Brockhaus-NT: s.v. 'Stammzellen') es: blastocito s.m. Cada una de las células de los organismos superiores que presentan capacidad para reproducirse durante tiempo indefinido en estado indife-

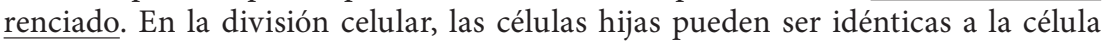
madre blastocítica (autorregeneración) o pueden emprender un proceso de diferenciación que las transforme en células especializadas. Esta diferenciación es inducida por el programa genético de las células o por parte de factores externos de diferenciación.Todos los tejidos y órganos del cuerpo, con excepción de los integrados por neuronas o miocitos (células que son incapaces de regenerarse), experimentan renovación en el plazo de pocos meses en virtud de los incesantes procesos de muerte y regeneración celular. Dado que las células especializadas han perdido la capacidad de reproducirse, la diferenciación a partir de blastocitos representa la única posibilidad de regeneración. (traducción del autor)

Comentario: Se registra en el fragmento original alemán confusión entre los términos (homófonos, pero no homógrafos) enddifferenzieren 'experimentar los blastocitos diferenciación hasta que se convierten en células especializadas (= ingl. terminal differentiation)' y entdifferenzieren 'experimentar las células (diferenciadas o especializadas) desdiferenciación (= ingl. dedifferentiation), ' confusión que aquí se corrige en la traducción española, la cual sigue las recomendaciones terminológicas de Navarro (2005: s.v. 'stem cell'). 


\subsubsection{Lapsos en la consignación de cantidades o unidades de medida}

En los textos científicos didácticos y divulgativos se reseñan con frecuencia cantidades y unidades de medida, las cuales, en algunos casos, son erróneas, lo que, como muestran los siguientes ejemplos, puede resultar más o menos obvio y puede deberse a causas diversas:

(8) de: Konstitutive Merkmale für die Insekten wie die sechs Beinpaare und die Körpergliederung in Kopf, Thorax und Abdomen sind zugleich sehr gute diagnostische Merkmale. (Einführung in die Phylogenetik und Systematik: 128)

pt: Caracteres constitutivos dos Insectos como os três pares de patas e a divisom corporal em cabeça, tórax e abdómen som, também, caracteres diagnósticos muito bons. (Manual de Evoluçom e Sistemática: 154)

(9) de: Während der Evolution der Wirbeltiere (Vertebrata) kam es zu einer Verdoppelung jener Genkomplexe, die für die Individualentwicklung (Ontogenese) verantwortlich sind. Daher sind Wirbeltier (z. B. Maus)-Embryonen durch 4 Hox-Gen-Cluster gekennzeichnet, während bei Invertebraten (z. B. Fliege) nur ein derartiger Hox-Gen-Komplex vorhanden ist (Swalla, 2006). (Evolutionsbiologie: 242) pt: Durante a evolução dos Vertebrata produziram-se duas duplicações de aqueles genes responsáveis pelo desenvolvimento individual (ontogénese), de modo que os embriões dos vertebrados (por exemplo, rato) são caracterizados por terem 4 complexos de genes hox, enquanto nos invertebrados (por exemplo, mosca) apenas está presente um complexo génico hox (Swalla, 2006). (Biologia Evolutiva: 376-377) Comentario: Corrección fundamentada en Storch, Welsch et al. 2007: 268 y en Wikipedia-en: s.v. 'Hox gene' (consulta: 7.7.2012).

(10) de: Diese Bakterien ertragen eine hohe Salinität, denn das Wasser des Mono Lake enthält $78 \mathrm{Gramm}$ Salz pro Liter, ist also mehr als doppelt so salzig wie Meerwasser. Dazu kommt, dass das Wasser des Mono Lake mit $p H 10$ stark alkalisch ist und 200 Mikromol Arsen enthält. (Naturw. Rdsch., 2/2011: 84)

es: Estas bacterias soportan una alta salinidad, pues el agua del lago Mono contiene 78 gramos de sal por litro, es decir, más del doble de la concentración presente en el agua del mar. Además, el agua del lago Mono, con un $p H$ de 10, es fuertemente alcalina y contiene 200 micromoles de arsénico por litro. (traducción del autor) Comentario: Tratándose de una concentración, la unidad de medida que aquí debe acompañar al módulo 200 es de naturaleza compuesta y se expresa como cantidad de sustancia por volumen de solución (aquí, $\mu \mathrm{mol} / \mathrm{l}$ ).

\subsubsection{Lapsos léxicos}

Consistentes en el uso de una palabra equivocada, que altera el sentido pertinente y origina segmentos falsos que el traductor debe evitar trasladar al texto de llegada. Los lapsos léxicos surgen con frecuencia por confusión del redactor al utilizar, en vez de la palabra apropiada, otra semántica o pragmáticamente relacionada con la correcta, pero no sinónima:

(11) en: The forests [of Finland] support abundant wildlife, including bear, wolf, wolverine, lynx, moose, and Finnish elk. Few reindeer survive in the wild; most are domesticated. (Enc. Brit.: s.v. 'Finland')

es: Los bosques [de Finlandia] albergan numerosos animales silvestres, como osos, lobos, glotones, linces, alces y venados de cola blanca. En cuanto a los renos, pocos restan en estado salvaje, y la mayoría están domesticados. (traducción del autor) Comentario: La voz inglesa elk denota, en la variedad europea de la lengua, el alce 
(Alces alces, designado como moose en el inglés norteamericano), y, en la variedad norteamericana de la lengua, el uapití (Cervus canadensis). En el original inglés (redactado en EeUu), el alce es designado como moose, de modo que elk, en Finnish elk, debería designar el uapití, pero este no habita el territorio finlandés. En la traducción española se corrige este dislate designativo mencionando la única especie de cérvido presente en Finlandia que es diferente del alce (orig. moose) y del reno (orig. reindeer), esto es, el venado de cola blanca o venado de Virginia (Odocoileus virginianus; ingl. white-tailed deer, Virginia deer, whitetail), introducido en Finlandia en 1935.

(12) de: Ein stark vergrößertes Brustbein [jen los peces de la fam. Gasteropelecidae!] dient als Ansatzfläche für zwei kräftige Brustmuskeln, die beidseitig zu den Brustflossen führen und den Kurzzeit-Ruderflug dieser Süßwasserfische ermöglichen. (Evolutionsbiologie: 201)

pt: Uma cintura escapular fortemente engrossada serve como superfície de fixação para dois potentes músculos peitorais, os quais se prolongam bilateralmente em direção às barbatanas peitorais e possibilitam os curtos voos dirigidos destes peixes dulciaquícolas. (Biologia Evolutiva: 313)

Comentario: Téngase en cuenta que, por una parte, en los peces no hay esternón, pues el esternón es un hueso evolucionado en los primeros tetrápodos como extensión de la cintura escapular (Wikipedia-en: s.v. 'sternum') y, por otra, que la cintura escapular y la musculatura pectoral son muy robustas en los peces voladores ( Schultergürtel und die Brustmuskulatur sind sehr kräftig.» [Wikipedia-de: s.v. 'Fliegende Fische']).

(13) de: An der Kathode spielt das Eisen $(\mathrm{Fe})$ die entscheidende Rolle. Beim Laden wird es vom zweiwertigen Fe2+ zum dreiwertigen $\mathrm{Fe} 3+$ reduziert: $\mathrm{LiFePO}_{4} \rightarrow \mathrm{FePO}_{4}+$ $\mathrm{Li}^{+}+\mathrm{e}^{-}$und beim Entladen wieder umgekehrt zu Fe2+ oxidiert: $\mathrm{FePO}_{4}+\mathrm{Li}^{+}+\mathrm{e}^{-} \rightarrow$ $\mathrm{LiFePO}_{4}$. (TechMax, 13: 2)

es: En el cátodo, es el hierro ( $\mathrm{Fe})$ el que desempeña el papel determinante. Así, durante la carga, el hierro divalente, $\mathrm{Fe} 2+$, es oxidado a hierro trivalente, $\mathrm{Fe} 3+$ $\left(\mathrm{LiFePO}_{4} \rightarrow \mathrm{FePO}_{4}+\mathrm{Li}^{+}+\mathrm{e}^{-}\right)$, y durante la descarga, el hierro trivalente es reducido para obtenerse $\mathrm{Fe} 2+: \mathrm{FePO}_{4}+\mathrm{Li}^{+}+\mathrm{e}^{-} \rightarrow \mathrm{LiFePO}_{4}$. (traducción del autor)

Comentario: En la redacción original se utilizan mal, confundidos, los términos reduzieren 'reducir' y oxidieren 'oxidar,' ya que un catión $\left(\right.$ como $\left.\mathrm{Fe}^{2+}\right)$ se oxida cuando ve aumentada su carga positiva (cede electrones: de $\mathrm{Fe}^{2+}$ a Fe ${ }^{3+}$ ), y se reduce cuando ve disminuida su carga positiva (gana electrones: de $\mathrm{Fe}^{3+} \mathrm{a} \mathrm{Fe}^{2+}$ ).

\subsubsection{Lapsos de redacción}

En algunos casos, es una redacción inadecuada (formulación errónea de una oración o de un miembro de oración) lo que determina el surgimiento de segmentos falsos en el texto de partida, como manifiestan los siguientes ejemplos:

(14) de: Dieser Vorschlag zur Planeten-Neudefinition wurde jedoch von vielen Astronomen abgelehnt, weil sie ihn für zu willkürlich hielten. Ihm zufolge gäbe es neben den acht klassischen Planeten noch mindestens vier weitere im Sonnensystem: Ceres, Eris, Pluto und dessen Großmond Charon, der mit Pluto zum Doppelplaneten befördert würde, weil der Schwerpunkt seiner Bahn um Pluto nicht außerhalb Plutos lokalisiert ist (der gemeinsame Drehpunkt von Erde und Mond liegt dagegen noch innerhalb des Erdkörpers). (Naturw. Rdsch., 1/2007: 8) es: Esta propuesta de nueva definición de planeta fue rechazada, sin embargo, por numerosos astrónomos, al considerarla demasiado arbitraria. Así, de acuerdo con ella, en el Sistema Solar existirían, además de los ocho planetas clásicos, al menos 
cuatro más: Ceres, Eris, Plutón y su gran satélite Caronte, el cual sería promovido, junto con Plutón, a la categoría de planeta doble, ya que el centro de gravedad de su órbita en torno a Plutón queda fuera de éste (mientras que, por ejemplo, el centro de rotación común de la Tierra y de la Luna se sitúa dentro de la esfera terrestre). (traducción del autor)

Comentario: En el texto original, la explicación de por qué se considera que Plutón y Caronte constituyen un planeta doble está mal redactada y contiene un contrasentido, debido a la presencia inconveniente de nicht («nicht außerhalb Plutos»), puesto que, en los planetas dobles, el centro de gravedad de la órbita del cuerpo menor en torno del mayor se encuentra fuera del cuerpo mayor, al contrario de lo que sucede en un sistema planeta-satélite (circunstancia bien explicada, con todo, en la oración encerrada entre paréntesis del original que sigue a la de redacción defectuosa).

\subsubsection{Errores conceptuales}

Los errores conceptuales, o de contenido, consisten en la presencia en el texto de partida de informaciones falsas o inexactas que no resultan, como en los tipos de deficiencias factuales anteriormente tratados, de meros lapsos expresivos. Una categoría especial de errores conceptuales es la representada por la presencia en el texto de partida de informaciones que ya se revelan anticuadas en el momento de la composición o publicación del original. Otro caso particular es el representado por las inexactitudes conceptuales debidas a simplificación pedagógica, aspecto abordado en la parte final de este subapartado. A seguir, se ilustra la naturaleza y tratamiento traductivo de los errores de contenido mediante una serie de ejemplos significativos:

(15) en: The single insect-eating species of this family [Mystacinidae] is confined to New Zealand. (McGraw-Hill Encyclopedia of Science \& Technology: s.v. 'Chiroptera') es: La única especie, omnívora, de esta família [Mystacinidae] se restringe a Nueva Zelanda. (traducción del autor)

Comentario: Aquí, el adjetivo insect-eating, que ejerce modificación explicativa, se vierte como omnívora, no como insectívora, porque la única especie actual (no extinta) de la fam. Mistacínidos (Mystacina tuberculata) se alimenta tanto de artrópodos como de carroña, frutos, polen y néctar de las flores (Mickoleit 2004: 522; Wikipedia-en: s.v. 'Mystacinidae').

(16) de: Innerhalb der pflanzenfressenden Säugetiere wurde das Wiederkäuen mehrmals entwickelt (Konvergenz): Auch Känguruhs, Kamele einschließlich Lamas (Unterordnung Tylopoda) und Schliefer käuen wieder und haben dafür speziell eingerichtete (unterteilte) Mägen. (Lexikon der Biologie: s.v. 'Wiederkäuer')

es: Entre los mamíferos fitófagos, la rumia se desarrolló varias veces (convergencia), de modo que también rumian algunos canguros y los camélidos (suborden Tylopoda), y, para ello, esos animales presentan un estómago especialmente acondicionado (subdividido). (traducción del autor)

Comentario: A pesar de tratarse de una creencia bastante extendida, es falso que los damanes (al. Schliefer; orden Hyracoidea) rumien, como oportunamente se denuncia en el manual de Zoología de los Vertebrados de Westheide y Rieger (Fischer 2004: 659: «Schliefer sind keine Wiederkäuer wie hartnäckig in der Literatur behauptet wird» [trad. autor: "Los damanes no son rumiantes, en contra de lo que obstinadamente se asevera en la literatura especializada"]) y en la enciclopedia de los mamíferos de Macdonald (2010: 87: «hyraxes do not ruminate»). De hecho, en Mickoleit (2004: 601, ilustr. 676) puede verse claramente que el estómago del damán Procavia capensis no está subdividido. 
(17) de: Darwin war bei seinem Besuch der Galapagosinseln insbesondere von der Vielfalt einer Vogelgruppe überrrascht, die ihm zu Ehren später als DarwinFinken bezeichnet wurde [...]. Umfangreiche Beobachtungen verschiedener Galapagosfinken, die alle von einer importierten Ursprungspopulation abstammen, überzeugten ihn später davon, dass Arten nicht konstant, sondern wandelbar seien. Die erst viele Jahre später von Darwin ausgearbeitete Deszendenztheorie hatte hier ihren Ursprung. (Evolutionsbiologie: 28)

pt: Durante a sua visita às ilhas Galápagos, Darwin ficou especialmente chocado pela diversidade de um grupo de aves que, posteriormente, e em sua honra, se viria a conhecer como os tentilhões-de-darwin [...]. As numerosas observações feitas dos diferentes tentilhões-das-galápagos, os quais descendem de uma população inicial importada a partir do continente, convenceriam mais tarde Darwin de que as espécies não são constantes, mas sim modificáveis. A teoria da descendência elaborada muitos anos depois por Darwin teve pois aqui a sua origem7. [...] [nota a pie de página del traductor:] 7. Na realidade, o grupo de aves das ilhas Galápagos que levou Darwin a duvidar da imutabilidade das espécies e a conceber a adaptação a ambientes diferentes como fonte de divergência e de especiação não foi o integrado pelos posteriormente denominados tentilhões-de-darwin ou tentilhõesdas-galápagos [...], nos quais ele pouco reparou, mas o integrado pelas diferentes espécies de imitadores (= sabiás) presentes no arquipélago (pássaros do género Nesomimus, da família Mimidae) [...]. (N. do T.) (Biologia Evolutiva: 45-46)

Comentario: En este caso, el traductor decidió insertar como observación propia (mediante nota documentada) la corrección efectuada en la traducción, para contribuir a divulgar la rectificación de un error muy extendido.

Los textos destinados a la enseñanza y divulgación de la ciencia experimentan en mayor o menor medida una simplificación (pedagógica o didáctica), que se identifica con las dimensiones «simplicidad» $y$ «perceptibilidad» de la inteligibilidad textual (Göpferich 2008: 163-188) y que se evidencia en la circunstancia de que estos textos presentan menor tecnicidad o grado de especialización que los propios de la comunicación intradisciplinaria (Baumann 1998: 731; Gutiérrez Rodilla 1998: 321; Niederhauser 1999: 120-128). Esta simplificación se consigue, entre otros aspectos, a través de la restricción del número de conceptos y términos manejados en el texto, lo que lleva con frecuencia a la enunciación de generalizaciones, evitándose dar cuenta de excepciones o casos particulares poco significativos. Por tal motivo, en la traducción de textos científicos didácticos y divulgativos, tales generalizaciones, en ausencia de circunstancias contextuales que las tornen inconvenientes, no deben juzgarse como deficiencias factuales (segmentos falsos o inexactos) y, por tanto, deben trasladarse sin modificación al texto de llegada, como muestra el siguiente ejemplo:

(18) en: The red pigment hemoglobin, containing iron, is found in all vertebrates and some invertebrates. (Enc. Brit.: s.v. 'blood')

es: La hemoglobina, pigmento respiratorio de color rojo que contiene hierro, se encuentra en todos los vertebrados y en algunos invertebrados. (traducción del autor) Comentario: La afirmación aquí considerada, dada la poca especialización de este texto (enciclopedia general), se revela legítima, aunque, estrictamente, es falsa (generalización simplificadora): "Antarktische Eisfische und die LeptocephalusLarven der Elopomorpha (Teleostei) [...] besitzen hämoglobin- und erythrocytenfreies Blut.» (Perry 2004: 91; traducción del autor: «Los peces de la familia Channichthyidae, antárticos, y las larvas leptocéfalas de los teleósteos del grupo Elopomorpha [...] poseen sangre desprovista de hemoglobina y de eritrocitos»; cf. tb. Wikipedia-en: s.v. 'haemoglobin'). 


\subsubsection{Discrepancia entre los componentes verbal e icónico del texto de partida}

En los textos destinados a la enseñanza y divulgación de la ciencia, el componente icónico, en forma de ilustraciones de diversos tipos (fotografías, dibujos, gráficos, mapas, etc.), suele tener un gran peso, relevancia que alcanza un máximo en los documentales científicos cinematográficos o televisivos (de carácter didáctico o divulgativo), en los cuales, de hecho, el componente verbal del texto queda subordinado a las imágenes ofrecidas. Los segmentos textuales de naturaleza verbal que se refieren a imágenes del texto, para ser correctos, además de reflejar la verdad conocida, deben armonizar o corresponderse con el respectivo segmento icónico, cuando este es correcto ${ }^{2}$. Con cierta frecuencia, entre algunos componentes icónicos y sus respectivos segmentos verbales del texto de partida se registra discrepancia y, en estos casos, el traductor debe determinar si alguno de los dos componentes es factualmente falso, para introducir la correspondiente corrección en el componente verbal o solicitar (del iniciador de la traducción) la corrección del componente icónico; si los dos componentes discrepantes son factualmente verdaderos, lo más fácil y económico suele ser que el traductor introduzca la corrección en el componente verbal. Ejemplos:

(19) de: Abb. 2.30. [...] Eis-, Wüsten- und Rotfuchs (Alopex lagopus, Vulpes rüppelli und Vulpes vulpes) bewohnen die arktische, subtropische bzw. gemäßigte Zone Europas. (Evolutionsbiologie: 54 )

pt: Figura 2.30. [...] A raposa-ártica (Alopex lagopus), o feneco ou raposa-dodeserto (Vulpes zerda) e a raposa-vermelha (Vulpes vulpes) habitam, respetivamente, zonas polares, subtropicais áridas e temperadas. (Biologia Evolutiva: 85)

Comentario: En la ilustración 2.30 aparece dibujada la cabeza de un feneco o zorro del desierto (nombre científico: Vulpes zerda; al. Fennek = Wüstenfuchs), no la de un zorro de Rüppell (nombre científico: Vulpes rueppelli; al. Rüppellfuchs $=$ Sandfuchs), lo que se aprecia (¡documentación!) en la relación de tamaños orejas/ rostro (mayor que en el zorro de Rüppell) y en la carencia de manchas oscuras en los lados del hocico (típicas del zorro de Rüppell). Además, en la traducción se prescinde de resaltar, como hace el original, la presencia en Europa del zorro rojo (el cual también habita la franja templada de Asia y el NO de África).

(20) de: [Pie de ilustración, la cual muestra las siluetas de un ser humano, de un cerdo y de un pato, pero no la de ningún galliforme:] Die Wahrscheinlichkeit für ein Reassortment steigt signifikant an, wenn verschiedene Populationen (z.B. Menschen und Schweine oder Hühnervögel) mit verschiedenen Virusvarianten in großer Zahl und Dichte die Möglichkeit zur gegenseitigen Infektion haben. (BioMax, 27: 3)

es: La probabilidad de que tenga lugar una recombinación vírica aumenta significativamente cuando diversas poblaciones (por ejemplo., de seres humanos, cerdos $\mathrm{y}$ aves de corral) que albergan diferentes variantes víricas, al convivir estrechamente, están sujetas a infecciones recíprocas. (traducción del autor)

Comentario: En el pie de ilustración original, a título de ejemplo, se alude a las aves galliformes, o gallináceas (al. Hühnervögel: gallinas, faisanes, pavos, etc.), pero en la ilustración figura la silueta de un pato, por tanto, de una anátida o anseriforme (al. Entenvögel). Esta discordancia entre los componentes textuales verbal e icónico se resuelve en la traducción, de modo económico, generalizando la referencia a todas las aves de corral, categoría en que se incluyen tanto las galliformes como los patos. 


\subsection{Deficiencias formales del texto de partida}

Clasificamos las deficiencias formales del texto de partida en dos categorías principales: a) deficiencias del texto de partida que dificultan su comprensión (en detrimento de la eficacia comunicativa), y b), deficiencias del texto de partida que perjudican el rigor expresivo (deficiencias de expresión).

\subsubsection{Deficiencias formales del texto de partida que dificultan su comprensión}

Este tipo de deficiencias formales puede desglosarse en las cuatro subcategorías siguientes: a) lapsos tipográficos que estorban el reconocimiento de las palabras; b) deficiencias en el nivel léxico o sintagmático que originan ambigüedad; c) deficiencias en el nivel oracional que originan ambigüedades o incoherencias, y d), deficiencias en la microestructura del texto de partida que perjudican la cohesión textual y la claridad expositiva.

\subsubsection{Lapsos tipográficos que estorban el reconocimiento de las palabras}

De los dos ejemplos siguientes, el primero muestra un lapso tipográfico que origina un elemento de por sí carente de sentido, mientras que, en el ejemplo siguiente, el error tipográfico origina un elemento falso de por sí dotado de sentido, el cual, sin embargo, resulta patentemente incompatible con su co(n)texto, por lo que no debería confundir a ningún traductor competente (cf. supra 3.1.1):

(21) en: Cobalt forms two well-defined binary compounds with oxygen: cobaltous, or cobalt(II) oxide, $\mathrm{CoO}$, and tricobalt textroxide [por tetroxide], or cobalto-cobaltic oxide, $\mathrm{Co}_{3} \mathrm{O}_{4}$. (Enc. Brit.: s.v. 'cobalt')

es: El cobalto forma dos compuestos binarios bien definidos con el oxígeno: el óxido cobaltoso, $\mathrm{u}$

óxido de cobalto (II), CoO, y el tetróxido de tricobalto, u óxido cobaltoso-cobáltico, $\mathrm{Co}_{3} \mathrm{O}_{4}$. (traducción del autor)

(22) en: Sometimes called phosphoric anhydride, or diphosphorus pentoxide, this compound can be

obtained in the from [por form] of a soft white powder or colourless crystalline solid. (Enc. Brit.:

s.v. 'phosphorus')

es: Este compuesto, designado como óxido de fósforo (v), pentóxido de (di)fósforo o anhídrido

fosfórico, puede obtenerse en forma de polvo blanco y blando o de sólido cristalino incoloro. (traducción del autor)

\subsubsection{Deficiencias en el nivel léxico o sintagmático que originan ambigüedad}

En el caso de los textos científicos compuestos en inglés y destinados a legos (propios de la comunicación especializada extradisciplinaria), cabrá conceptuar como de redacción disfuncional aquellos pasajes en que la ambigüedad estructural en la segmentación de sintagmas nominales complejos, o en el alcance de la modificación nominal, siendo evitable mediante una simple formulación alternativa, fácilmente puede originar interpretaciones erróneas (Schmitt 1999a: 92-94; Garrido 2013). Constituye un ejemplo de esta clase de deficiencias formales: 
(23) en: Some fish and amphibians use their thin, moist, vascular skin for respiratory exchange. (Enc. Brit.: s.v. 'respiration')

es: Los anfibios y algunos peces utilizan su piel, fina, húmeda y profusamente vascularizada, para los intercambios respiratorios. (traducción del autor)

Comentario: En el original se registra ambigüedad estructural en relación con el alcance de la modificación nominal ejercida por el determinante some. Aquí, la traducción literal en español no sería ambigua, sino directamente falsa («Algunos peces y anfibios [= algunos anfibios] utilizan [...].» = sólo algunos peces y sólo algunos anfibios presentan respiración cutánea), de modo que la versión española debe transmitir la información verdadera mediante una de las dos formulaciones siguientes: «Algunos peces y los anfibios [= todos los anfibios]» $\mathrm{O}$ «Los anfibios [= todos los anfibios] y algunos peces».

\subsubsection{Deficiencias en el nivel oracional que originan ambigüedades o incoherencias}

Una redacción deficiente suscitada por la disposición inadecuada de los elementos de la oración, o por la presencia indebida u omisión de algún elemento, puede originar en el texto de partida pasajes ambiguos o incoherentes (contradictorios), que el traductor no debe transferir al texto de llegada, como ilustran los siguientes ejemplos:

(24) en: More primitive species [de cecilias] lay eggs that are guarded by the female; the eggs hatch into free-living larvae. Other species lay eggs but are not direct developers. (Enc. Brit.: s.v.'caecilian')

es: Las especies más primitivas [de cecilias] ponen huevos que son protegidos por la hembra. Algunas especies ovíparas presentan desarrollo directo, mientras que, en otras, de los huevos eclosionan larvas de vida libre. (traducción del autor)

Comentario: En el original se lee «unas especies ponen huevos y presentan desarrollo indirecto (tienen larvas), otras especies ponen huevos pero no presentan desarrollo directo». Por consiguiente, sobra, en el original, el adverbio not. (Documentación: Haas 2004: 323-324 y Wikipedia-en: s.v. 'caecilian' [consulta: 7.7.2012])

(25) de: Begünstigt werden Algenblüten durch vermehrten Nährstoffeintrag in Seen und Teichen etwa durch die Landwirtschaft und durch warme Klimabedingungen. (Naturw. Rdsch., 1/2013: 36)

es: El surgimiento de eflorescencias algales se ve favorecido por temperaturas elevadas y por la entrada masiva de nutrientes en lagos y lagunas (causada, por ejemplo, por las actividades agrícolas). (traducción del autor)

Comentario: Con la redacción del original, se corre el riesgo de que el lector interprete indebidamente el segundo miembro del complemento agente de begünstigt werden (esto es, «warme Klimabedingungen»), como si fuese el segundo miembro del complemento causal de vermehrten Nährstoffeintrag; para evitar este riesgo, en nuestra traducción situamos «temperaturas elevadas» como primer miembro del complemento agente de verse favorecido. Por otra parte, también procedemos en la traducción a corregir una deficiencia expresiva de carácter léxico presente en el original, que deriva de confundir condiciones climáticas con condiciones meteorológicas.

\subsubsection{Deficiencias en la microestructura del texto de partida que perjudican} la cohesión textual y la claridad expositiva

En algunos casos, la distribución de los elementos discursivos por oraciones y párrafos que muestra el texto de partida (microestructura) perjudica la cohesión textual 
y detrae claridad y eficacia a la comunicación, por lo que el traductor debe corregir en el texto de llegada tal circunstancia, reordenando los elementos textuales y modificando la configuración oracional del texto de partida, como manifiesta el ejemplo siguiente:

(26) en: In addition to respiratory activities, the lungs perform other bodily functions. Through them, water, alcohol, and pharmacologic agents can be absorbed and excreted. Normally, almost a quart of water is exhaled daily; anesthetic gases such as ether and nitrous oxide can be absorbed and removed by the lungs. (Enc. Brit.: s.v. 'lung')

es: Además de la actividad respiratoria, los pulmones desempeñan otras funciones fisiológicas. Así, a través de ellos el organismo puede absorber y eliminar agua (normalmente, los pulmones exhalan casi un litro de agua cada día), alcohol, fármacos y gases anestésicos como el éter y el óxido nitroso. (traducción del autor) Comentario: Desplazamiento de elementos en la traducción para incrementar la cohesión textual y claridad expositiva.

\subsubsection{Deficiencias del texto de partida que perjudican el rigor expresivo}

Esta clase de deficiencias formales (deficiencias de expresión) puede dividirse en las cuatro subcategorías siguientes: $\boldsymbol{a}$ ) ruptura de las convenciones ortotipográficas; $\boldsymbol{b})$ lapsos tipográficos en la consignación de datos; $\boldsymbol{c}$ ) errores léxicos, y $\boldsymbol{d}$ ), redacción deficiente.

\subsubsection{Ruptura de las convenciones ortotipográficas}

Además de prestar atención a las normas ortotipográficas generales (referentes al uso de signos y estilos tipográficos), en la traducción de textos científicos, el traductor debe celar por el cumplimiento en el texto de llegada de normas ortotipográficas de carácter especializado, como muestran los ejemplos siguientes:

(27) en: [...] density (gray form [of arsenic]) $5.73 \mathrm{~g} / \mathrm{cc}$ at $14^{\circ} \mathrm{C}\left(57^{\circ} \mathrm{F}\right)$. (Enc. Brit.: s.v. 'arsenic')

es: [...] densidad (forma gris): $5,73 \mathrm{~g} / \mathrm{cm} 3$ a $14{ }^{\circ} \mathrm{C}$. (traducción del autor)

Comentario: En un contexto químico, el símbolo correspondiente al centímetro cúbico es $\mathrm{cm}^{3}$, no $c c$.

(28) de: Erst 1991 wurde vor der peruan[ischen]. Küste eine neue Art entdeckt (Mesoplodon peruvianus), die der Gattung Zweizahnwale zugeordnet wurde. (Brockhaus Enzyklopädie: s.v. 'Wale, Cetacea')

es: Aún en 1991 y en 2002 se descubrieron, en las costas de Perú y de California, dos nuevas especies de cetáceos, pertenecientes a la familia Zifíidos, respectivamente, el zifio peruano o menor (Mesoplodon peruvianus) y el zifio de Perrin $(\underline{M}$. perrini). (traducción del autor)

Comentario: Los nombres científicos de especie deben escribirse en cursiva (nuestra traducción incluye una actualización informativa).

\subsubsection{Lapsos tipográficos en la consignación de datos}

Aunque su producción está sometida a procesos de revisión editorial, los textos científicos didácticos y divulgativos presentan con alguna frecuencia, además de rupturas de las convenciones ortotipográficas (consideradas en el apartado anterior), también lapsos tipográficos que desfiguran y afean nombres propios (antropónimos [extranjeros], títulos de obras [en lengua extranjera], denominaciones vernáculas y, 
sobre todo, científicas de seres vivos, etc.) y otras palabras que constituyen datos (ver supra ejemplo [6]). En estos casos, el traductor debe reconocer el correspondiente elemento desfigurado y restituirlo en su forma correcta, como muestran los siguientes ejemplos:

(29a) de: Die einzelligen Vertreter der Chlorarachinophyta [...]. (Evolutionsbiologie: 154)

pt: Por conseguinte, os representantes, unicelulares, dos Chlorarachniophyta [...]. (Biologia Evolutiva: 238)

(29b) de: Das Vietnamesische Wildrind (Pseudoryx nghetinhensis, Abb.) ist eines der wohl seltensten Tiere der Welt. Die auch Soala genannte Art wurde erst 1993 entdeckt und vorwiegend anhand weniger Schädel geschrieben. (Naturw. Rdsch., 8/2012: 422)

es: El buey de $\mathrm{Vu}$ Quang (Pseudoryx nghetinhensis, v. ilustr.) es, con certeza, uno de los animales más escasos del mundo. Esta especie, también designada como saola, no fue descubierta y descrita hasta 1993, principalmente con base en unos pocos cráneos. (traducción del autor)

Comentario: Corrección de errores tipográficos que desfiguran denominaciones (científicas y vernácula) de grupos de organismos.

\subsubsection{Errores léxicos}

Se trata de la utilización indebida en el texto de partida de ciertos vocablos, o de la falta indebida de un vocablo, que perjudica el rigor expresivo, como muestran los siguientes ejemplos:

(30) en: Upon cooling, fluorine becomes a yellow liquid at $-188^{\circ} \mathrm{C}\left(-306^{\circ} \mathrm{F}\right)$ and freezes at about $-219.62^{\circ} \mathrm{C}\left(-362^{\circ} \mathrm{F}\right)$. (Enc. Brit.: s.v. 'fluorine')

es: Cuando es enfriado, el flúor se transforma en un líquido amarillo a aprox. $-188^{\circ} \mathrm{C}$ y solidifica a $-219,62{ }^{\circ} \mathrm{C}$. (traducción del autor)

Comentario: Temperatura de ebullición del flúor: $-188,12{ }^{\circ} \mathrm{C}$; temperatura de congelación: $-219,62{ }^{\circ} \mathrm{C}$.

(31) de: Fluor wurde erstmals 1886 von H. Moissan bei der Elektrolyse von wasserfreier Flusssäure in einem Platingefäß gewonnen. (Brockhaus-NT: s.v. 'Fluor')

es: El flúor fue obtenido por primera vez por H. Moissan en 1886, mediante la electrolisis de fluoruro de hidrógeno anhidro efectuada en un recipiente de platino. (traducción del autor)

Comentario: La expresión wasserfreie Flusssäure, que consta en el original, es incorrecta, ya que Flusssäure (= Fluorwasserstoffsäure) significa 'ácido fluorhídrico,' y éste siempre contiene agua y nunca puede ser anhidro, porque se trata de una disolución acuosa de fluoruro de hidrógeno; lo correcto es, por tanto, fluoruro de hidrógeno anhidro (al. wasserfreier Fluorwasserstoff).

(32) de: Excimer-Laser, Excited Dimer-Laser: Laser, dessen Lasermedium aus einem Dimer besteht. [...] Am häufigsten sind Verbindungen von Halogeniden und Edelgasen, z. B. $\mathrm{ArF}^{*}, \mathrm{KrF}^{*}, \mathrm{XeF}^{*}$ und $\mathrm{XeCl}^{*}$ ( ${ }^{*}$ bedeutet: angeregter Zustand des Moleküls). (Naturw. Rdsch., 9/2010: 454)

es: Láser de tipo excimer (ingl. excited dimer-laser): láser cuyo medio activo consiste en un dímero. [...] Los más frecuentes son los compuestos integrados por halógenos y gases nobles, como, por ejemplo, $\mathrm{ArF}^{*}, \mathrm{KrF}^{*}, \mathrm{XeF}^{*}$ y XeCl${ }^{*}$ (el símbolo * indica 'estado excitado de la molécula'). (traducción del autor)

Comentario: Sustitución indebida en el original de Halogen(e) (= halógeno(s)) por Halogenid(e) (= halogenuro(s)). Lo correcto sería «Am häufigsten sind Verbindungen 
von Halogenen und Edelgasen» ('compuestos integrados por halógenos y gases nobles') o "Am häufigsten sind Edelgas-Halogenide» ('halogenuros de los gases nobles').

\subsubsection{Redacción deficiente}

Con alguna frecuencia, las deficiencias formales del texto de partida se manifiestan en pasajes cuya redacción contraría los principios de precisión, claridad y concisión (y elegancia expresiva) de la comunicación especializada, defectos que el traductor debe corregir en el texto de llegada, como muestran los ejemplos siguientes:

(33) en: Many species [de cecilias] are viviparous, giving birth to miniature adults following nutrition in the oviduct by the maternal partner. (Enc. Brit.: s.v. 'caecilian') es: Muchas especies [de cecilias] son vivíparas, de modo que la hembra pare crías que parecen adultos en miniatura tras un período en que estas son alimentadas en el oviducto materno. (traducción del autor)

Comentario: La afirmación del original «dan a luz adultos en miniatura» no tiene sentido, pues nunca las crías son adultos, sino individuos jóvenes (de pequeño tamaño, que parecen por la forma adultos).

(34a) en: The cellulose and polymer carbohydrates of seaweeds are made into such thickening agents as agar, algin, and carrageenan. (Enc. Brit.: s.v. 'commercial fishing')

es: La celulosa y otros hidratos de carbono poliméricos de las algas marinas se transforman en los agentes espesantes agar, alginatos y carragenina. (traducción del autor)

(34b) de: Mineralsäuren und Alkalilaugen greifen Aluminium heftig an, konzentrierte Salpetersäure hingegen nicht. (Brockhaus-NT: s.v. 'Aluminium')

es: Las lejías alcalinas y los ácidos minerales, excepto el nítrico concentrado, atacan enérgicamente al aluminio. (traducción del autor)

(34c) de: Weiterhin bewohten gestielte Seelilien (Crinoiden), die zu Kolonien vereinigten Moostierchen (Bryozoen), verschiedene Stachelhäuter (Seesterne und Seeigel) und andere Invertebraten die algenreichen Meere. (Evolutionsbiologie: 98)

pt: Além disso, povoavam os mares ricos em algas diversos equinodermos, como crinoides pedunculados (lírios-do-mar), estrelas-do-mar e ouriços-do-mar, briozoários associados em colónias e outros invertebrados. (Biologia Evolutiva: 151-152)

Comentario: En estos tres ejemplos, en aras de la precisión y claridad, el traductor introduce modificaciones en los segmentos del texto de llegada relativos a la celulosa -pues la celulosa también es un hidrato de carbono polimérico y, de hecho, un alto polímero-, al ácido nítrico (al. Salpetersäure) -que también es un ácido mineral (inorgánico) - y a los lirios de mar (al. Seelilien), que también son equinodermos.

(35) en: The toaster and thermocouple, and forward and reverse osmosis, are mirrorimage processes. They are connected by the so-called reciprocity relation, the formulation of which won Onsager the 1968 Nobel Prize in Chemistry. (Sci. Am., 11/2008: 43)

es: La relación existente entre el funcionamiento de un tostador y el de un termopar, y entre la ósmosis y la ósmosis inversa, es similar a la que se registra entre imágenes especulares, ya que tales procesos están vinculados por la denominada relación de reciprocidad, cuya formulación valió a Onsager la concesión en 1968 del Premio Nobel de Química. (traducción del autor) 
Comentario: Un tostador y un termopar no son procesos, como se afirma en el original, aunque sí lo es su funcionamiento.

\section{Conclusiones}

Con el objetivo de categorizar las deficiencias o defectos del texto de partida en la traducción comunicativa de textos destinados a la enseñanza y divulgación de la ciencia, es necesario delimitar con precisión tal concepto, lo cual permite aquí distinguir las deficiencias textuales propiamente dichas de: a) los pasajes que suscitan en el traductor la introducción de mejoras (a diferencia de las correcciones, meramente facultativas); b) las informaciones (ostensivamente) falsas incorporadas de modo ocasional a esos textos con sana finalidad humorística; c) la presencia de datos anticuados sobrevenida por un desfase temporal significativo entre la producción del texto de partida y la del texto de llegada, y d) las inexactitudes suscitadas por una legítima y oportuna simplificación pedagógica. En este sentido, cabe constatar, a partir de nuestra dilatada experiencia como lectores y traductores de textos científicos didácticos y divulgativos, que éstos, a pesar de ser publicados tras una revisión editorial, presentan, no raramente, con considerable frecuencia, deficiencias de variada naturaleza.

Las deficiencias presentes en el texto de partida destinado a la enseñanza o divulgación de la ciencia, las cuales deben corregirse en el (cuerpo del) texto de llegada en el marco de la traducción comunicativa, pueden clasificarse -de forma más específica y clara que en las propuestas de Schmitt (1999a) y de Horn-Helf (1999)-, siguiendo un criterio basado en la manifestación y en la causa de las deficiencias, en deficiencias factuales, cuando se oponen a la designación de la verdad conocida o a la adecuada correspondencia entre los componentes verbal e icónico del texto, y en deficiencias formales, cuando perjudican el rigor expresivo o la eficacia comunicativa. Las deficiencias factuales pueden adscribirse a las subcategorías «lapsos tipográficos que alteran el sentido pertinente», «lapsos en la consignación de cantidades o unidades de medida», «lapsos léxicos», «lapsos de redacción», «errores conceptuales o de contenido» $\mathrm{y}$ «discrepancia entre los componentes verbal e icónico del texto», mientras que las deficiencias formales se dividen en dos subcategorías principales: deficiencias del texto de partida que dificultan su comprensión (en detrimento de la eficacia comunicativa) y deficiencias del texto de partida que perjudican el rigor expresivo; a las primeras se adscriben los «lapsos tipográficos que estorban el reconocimiento de las palabras», «deficiencias en el nivel léxico o sintagmático que originan ambigüedad», «deficiencias en el nivel oracional que originan ambigüedades o incoherencias» $\mathrm{y}$ «deficiencias en la microestructura del texto de partida que perjudican la cohesión textual y la claridad expositiva», y a las segundas, "ruptura de las convenciones ortotipográficas», «lapsos tipográficos en la consignación de datos», «errores léxicos»y «redacción deficiente».

Como testimonia la rica muestra de ejemplos aquí ofrecida, la detección de las deficiencias del texto de partida (y su corrección en el texto de llegada) constituye un importante problema de la traducción de textos científicos didácticos y divulgativos, cuya resolución plantea exigencias cognitivas diversas. Así, para la detección de las deficiencias textuales (factuales o formales), según los casos, será necesario: a) efectuar un mero análisis co(n)textual o lógico que preste atención a incoherencias, asimetrías 
o contradicciones presentes en el texto de partida, como en nuestros ejemplos 7, 9, $14,24,25$ y 30; b) recurrir a la cultura general, como en nuestros ejemplos 8,10, 20 y 35; c) movilizar conocimientos de especialidad básicos, como en nuestros ejemplos $12,13,27,28,31,32$ y $34 \mathrm{a}-\mathrm{c}$; d) movilizar conocimientos de especialidad avanzados, procediendo a la pertinente documentación, como en nuestros ejemplos 11,15, 16, 17,18 y 19.

En este punto, difícil será exagerar la importancia de que el traductor de textos científicos y, en general, el de textos especializados, lea el texto de partida, incluso el ya editorialmente publicado, con ojo crítico, atento a la eventualidad -como acabamos de ver, nada rara- de que el original contenga deficiencias factuales o formales, las cuales, claro está, no deberán ser transferidas al texto de llegada. A este respecto, dada la falta de pericia en la redacción de textos que muestran con cierta frecuencia los profesionales del ámbito científico-técnico, para el traductor de textos científicos didácticos y divulgativos resultará aconsejable prestar especial atención a aspectos compositivos del original como la presencia de pasajes ambiguos, oscuros o contradictorios, o a eventuales problemas de cohesión y microestructura textual; también, en general, valdrá la pena reparar en aquellos aspectos particularmente susceptibles al lapso, como la consignación de cantidades y unidades de medida y la escritura de nombres propios y palabras extranjeras.

En cuanto a las deficiencias factuales, su descubrimiento en el texto de partida y su corrección en el de llegada exigen, como vimos, la movilización de unos conocimientos que oscilan entre los propios de la «cultura general» y los de una determinada especialidad científica a un nivel más o menos avanzado. Si, como afirma Schmitt (1999a: 104), el traductor debe disponer de los suficientes conocimientos de la especialidad de los textos con que trabaja para no incorporar a su traducción defectos absurdos presentes en el texto de partida, para la expurgación de deficiencias factuales no absurdas -añadimos nosotros-, el traductor deberá aplicar una sana desconfianza, o curiosidad intelectual, que lo lleve a intentar documentar por su cuenta alguna parte de los datos reseñados en el texto original, operación, ésta, que, como evidencia el presente trabajo (ver, entre otros, ejemplos 9, 12, 15 y 24), hoy se ve gozosamente facilitada y potenciada gracias a Internet, a su universo textual y, en particular, a su enciclopedia Wikipedia. ${ }^{3}$

\section{NOTAS}

1. Junto a los artículos lexicográficos de broma (al. Scherzeinträge), una variedad especial de artículo lexicográfico falso o fingido (ingl. fictitious entry, fake entry; al. Nihilartikel, fingierter

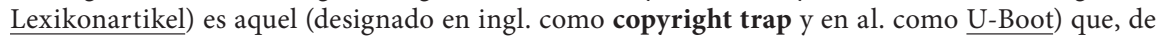
modo intencionado, contiene un elemento informativo declaradamente falso con la finalidad de delatar eventuales plagios o copias ilegítimas de la obra lexicográfica.

2. Así, por ejemplo, enunciados como «Manatees feed on plants» $\mathrm{y}$ «A manatee cruises the shallows in search of sea grass to graze on", que son verdaderos en el mundo real, serían factualmente errados en una imagen o secuencia que mostrase sirenios en un documental sobre la fauna del Océano Pacífico, pues los sirenios que viven en el Pacífico no son manatíes, sino dugongos.

3. En determinados círculos se ha desacreditado a Wikipedia por la escasa calidad de algunos de sus artículos de los ámbitos de las ciencias sociales y de las humanidades (cf., por ejemplo, Gourdain, O’Kelly et al. 2008). Sin embargo, basándonos en nuestra experiencia (reflejada, de hecho, en el presente artículo), podemos afirmar que, por lo menos, las versiones inglesa y alemana de Wikipedia ofrecen, en general, información rica, fiable y actualizada en el campo de las ciencias naturales. 


\section{REFERENCIAS}

Baumann, Klaus-Dieter (1998): Fachsprachliche Phänomene in den verschiedenen Sorten von populärwissenschaftlichen Vermittlungstexten. In: Lothar Hoffmann, Hartwig KaLVERKÄMPER y Herbert Ernst WIEgAND, dir. Fachsprachen. Ein internationales Handbuch zur Fachsprachenforschung und Terminologiewissenschaft / Languages for Special Purposes. An International Handbook of Special-Language and Terminology Research, vol. 1. Berlín/ Nueva York: Walter de Gruyter, 728-735.

Fischer, Martin S. (2004): Hyracoidea, Schliefer. In: Wilfried Westheide y Reinhard Rieger, dir. Spezielle Zoologie. Teil 2: Wirbel- oder Schädeltiere. Heidelberg: Spektrum Akademischer Verlag, 655-660.

Fleischmann, Eberhard y Sснмitt, Peter A. (2004): Fachsprachen und Übersetzung. In: Harald Kittel, Armin Paul Frank, Norbert Greiner et al., dir. Übersetzung / Translation / Traduction. Handbücher zur Sprach- und Kommunikationswissenschaft, n. ${ }^{\circ}$ 26.1. Berlín/Nueva York: Walter de Gruyter, 531-542.

Garrido, Carlos (2010): Modificaciones substanciales en la traducción de artículos de tema científico-técnico de la Encyclopædia Britannica: implicaciones para la didáctica y la crítica de la traducción científico-técnica. Hermēneus. 12:93-120.

GARrido, Carlos (2013): Alcance e restritividade da modificação nominal como problema da tradução técnico-científica de inglês e de alemão para português e espanhol. Sendebar. 24:107-126.

GöPFERICH, Susanne (2008/2002): Textproduktion im Zeitalter der Globalisierung. Entwicklung einer Didaktik des Wissenstransfers. Tubinga: Stauffenburg Verlag.

Gourdain, Pierre, O’Kelly, Florence, Roman-Amat, Béatrice et al. (2008): La revolución Wikipedia. (Traducido por Magalí Martínez Solimán). Madrid: Alianza Editorial.

Gutiérrez Rodilla, Bertha M. (1998): La ciencia empieza en la palabra. Análisis e historia del lenguaje científico. Barcelona: Ediciones Península.

HaAs, Alexander (2004): Lissamphibia, Amphibien. In: Wilfried Westheide y Reinhard Rieger, dir. Spezielle Zoologie. Teil 2: Wirbel- oder Schädeltiere. Heidelberg: Spektrum Akademischer Verlag, 311-340.

HönIG, Hans G. (1998): Übersetzen lernt man nicht durch Übersetzen. Ein Plädoyer für eine Propädeutik des Übersetzens. Fremdsprachen lehren und lernen (FLuL). 17:154-167.

Horn-Helf, Brigitte (1999): Technisches Übersetzen in Theorie und Praxis. Tubinga: A. Francke Verlag.

House, Juliane (1981): A Model for Translation Quality Assessment. Tubinga: Gunter Narr Verlag. Macdonald, David, dir. (2010): The Encyclopedia of Mammals. Oxford: Oxford University Press.

Mickoleit, Gerhard (2004): Phylogenetische Systematik der Wirbeltiere. Múnich: Verlag Dr. Friedrich Pfeil.

Navarro, Fernando A. (2005): Diccionario crítico de dudas inglés-español de medicina. Madrid: McGraw-Hill/Interamericana.

NiederhAUSER, Jürg (1999): Wissenschaftssprache und populärwissenschaftliche Vermittlung. Forum für Fachsprachen-Forschung, 53. Tubinga: Gunter Narr Verlag.

Nord, Christiane (1989): Loyalität statt Treue. Vorschläge zu einer funktionalen Übersetzungstypologie. Lebende Sprachen. 34(3):100-105.

Nord, Christiane (1997): A functional typology of translations. In: Anna Trosвorg, dir. Text Typology and Translation. Benjamins Translation Library, vol. 26. Amsterdam/Filadelfia: John Benjamins, 43-66.

Nord, Christiane (2012): Texto base-texto meta: un modelo funcional de análisis pretraslativo. (Traducido y adaptado por Christiane NorD). Castelló de la Plana: Universitat Jaume I.

Perry, Steven F. (2004): Herz und Blutgefäßsystem. In: Wilfried Westheide y Reinhard Rieger, dir. Spezielle Zoologie. Teil 2: Wirbel- oder Schädeltiere. Heidelberg: Spektrum Akademischer Verlag, 90-106.

Reiss, Katharina y Vermeer, Hans J. (1991): Grundlegung einer allgemeinen Translationstheorie. Tubinga: Max Niemeyer Verlag. 
Schmitт, Peter A. (1999a): Translation und Technik. Tubinga: Stauffenburg Verlag.

Schmitt, Peter A. (1999b): Defekte im Ausgangstext. In: Mary Snell-Hornby, Hans G. Hönig, Paul Kussmaul et al., dir. Handbuch Translation. 2. ${ }^{a}$ ed. Tubinga: Stauffenburg Verlag, 147-151.

Sснмітт, Peter A. (2005): Grenzen der Kreativität. Lebende Sprachen. 3:104-111.

SтоRсн, Volker, Welsch, Ulrich y Wink, Michael (2007): Evolutionsbiologie. Berlín/Heidelberg: Springer Verlag.

ZiegleR, Andreas (2010): Jubiläum der Steinlaus. Naturwissenschaftliche Rundschau. 12:655-656.

\section{ANEXO: FUENTES DE LOS EJEMPLOS}

Artículos de enciclopedia y de diccionario especializado:

The New Encyclopeedia Britannica (15.a ed., 1994), «Micropædia» [se cita como Enc. Brit.]: 'arsenic,' 'blood,' 'caecilian,' 'cobalt,' 'commercial fishing,' 'Finland,' 'fluorine,' 'lung,' 'phosphorus,' 'respiration.'

Brockhaus Enzyklopädie (19. a ed., 1986): 'Wale, Cetacea.'

Brockhaus Naturwissenschaft und Technik (2003) [se cita como Brockhaus-NT]: 'Aluminium,' 'Fluor,' 'Stammzellen.'

Lexikon der Biologie (1999-2004): 'Wiederkäuer.'

McGraw-Hill Encyclopedia of Science \& Technology (7. a ed., 1992): 'Chiroptera.'

Pschyrembel. Klinisches Wörterbuch (261. a ed., 2007): 'Steinlaus.'

\section{Libros didácticos:}

Ax, Peter (1988): Systematik in der Biologie. Darstellung der stammesgeschichtlichen Ordnung in der lebenden Natur. Uni-Taschenbuch 1502. Stuttgart: Gustav Fischer Verlag.

Ax, Peter (1999): La sistemática biológica. Plasmación del orden filogenético del mundo vivo. (Traducido por Carlos Garrido). Vigo: Serviço de Publicaçons da Universidade de Vigo.

Kutschera, Ulrich (2008): Evolutionsbiologie. Stuttgart: Eugen Ulmer Verlag.

Kutschera, Ulrich (2013): Biologia Evolutiva. (Traducido por Carlos Garrido). Lisboa: Fundação Calouste Gulbenkian.

Sudhaus, Walter y Rehfeld, Klaus (1992): Einführung in die Phylogenetik und Systematik. Stuttgart: Gustav Fischer Verlag.

Sudhaus, Walter y Rehfeld, Klaus (2002): Manual de Evoluçom e Sistemática. (Traducido por Carlos GARrido). Santiago de Compostela: Edicións Laiovento.

\section{Artículos de divulgación:}

BecK, Christina (2011): Sein oder Nichtsein - wie Viren ihr Überleben sichern. BioMax. 27.

BorCHARD-TuCH, Claudia (2010): Lasermedizin. Naturwissenschaftliche Rundschau. 9:453-458.

Fürchterlich, Ottokar H. (2007): EU plant Großstaudamm am Oberrhein. Naturwissenschaftliche Rundschau. 4:207.

Martin, Peter (2012): Monitoring seltener Wirbeltiere mittels Egelblut. Naturwissenschaftliche Rundschau. 8:422.

Mebs, Dietrich (2013): Missbildungen durch Blaualgen. Naturwissenschaftliche Rundschau. 1:36.

Rubí, J. Miguel (2008): The Long Arm of the Second Law. Scientific American. 11:40-45.

Trueb, Lucien F. (2011): Bakterielle „Arsenesser“ im Mono Lake? Naturwissenschaftliche Rundschau. 2:84-85.

VAas, Rüdiger (2007): Pluto ist kein Planet mehr. Eine astronomische Definition und ihre Konsequenzen. Naturwissenschaftliche Rundschau. 1:5-9.

Wengenmayr, Roland (2008): Alles ganz schön oberflächlich - Warum Forscher noch mehr über Katalyse wissen wollen. TechMax. 10.

Wengenmayr, Roland (2010): Eine volle Ladung Energie - elektrisierende Ideen für leistungsfähigere Batterien. TechMax. 13. 